Bangladesh Journal of Anatomy July 2012, Vol. 10 No. 2 pp 68-72

\title{
Age \& Sex Related Change in the Shape of the Human Pituitary Gland
}

\author{
Mushfika Rahman', Shamim Ara², Halima Afroz ${ }^{3}$, Anjuman Ara Sultana ${ }^{4}, K^{2}$ ij Fatema ${ }^{5}$, Nurun Nahar
}

\begin{abstract}
Context: The pituitary gland produces several hormones that regulate growth, metabolism and reproduction. Deviations from the normal functions of the gland certainly derange the harmony of life. Therefore, this study is important to determine the disease conditions of the gland and also for diagnosis and treatment of diseases of other endocrine organs. Many studies suggested that changes in the endocrine milieu may be reflected in pituitary morphology. The pituitary height in females was significantly greater than that in males. The decline in pituitary height with age may also reflect the process of aging and a physiological pituitary atrophy. Dynamic changes occur in the size, shape and signal intensity of the pituitary gland during life. These changes reflect the complex hormonal environment of the gland and are most pronounced at times of hormonal flux, such as menarche and pregnancy. The appearance of the pituitary gland in magnetic resonance imaging (MRI) of newborn infants differs from that of older children and adults. Previous observers have noted changes in the shape of the pituitary gland at different stages of life, which also reflect concurrent changing of hormonal level.
\end{abstract}

Objective: To identify any variation of shape of the pituitary gland in relation to age \& sex.

Type of Study: A cross-sectional analytical type of study.

Place \& Period of Study: Department of Anatomy, Dhaka Medical College, Dhaka, from July 2009 to June 2010.

Materials: About 60 (40 male and 20 female) postmortem human pituitary glands were collected from unclaimed dead bodies that were under examination in the morgue of the Department of Forensic Medicine, Dhaka Medical College Dhaka. The study was approved by the Ethical Review Committee (ERC) of Dhaka Medical College.

Methods: The samples were divided into four groups. i.e. Group-A (20-29 years), Group-B (30-39 years), Group-C (40-49 years) and Group-D (50-59 years). The shape was recorded according to the grading system of Elster et al.(1990), such as- a) Grade 1-Concave, b) Grade 2- Mildly concave, c) Grade 3 - Flat, d) Grade 4 - Mildly convex, e) Grade5-Moreconvex/rounded/spherical.

Results: Grade 1 was found in 1(2.5\%) male sample of group $B$ and $C \& 1(5 \%)$ in female sample of group $A$. Grade 2 was noted in $3(7.5 \%), 2(5 \%), 3(7.5 \%)$ and $1(2.5 \%)$ male samples of group $A, B, C$ and $D$ respectively. Grade 3 was found in $4(10 \%), 5(12.5 \%), 4(10 \%)$ and $1(2.5 \%)$ male samples of group $A, B, C$ and $D$ respectively and about $1(5 \%), 2(10 \%)$ and $1(5 \%)$ female samples of group $A, B$ and $C$ respectively. Grade 4 was noted in $2(5 \%), 7(17.5 \%), 1(2.5 \%)$ and $1(2.5 \%)$ male samples of group $A, B, C$ and $D$ respectively and in $6(30 \%), 3(15 \%)$ and $1(5 \%)$ female samples of group $A, B$ and $C$ respectively. Grade 5 was noted in $2(5 \%)$ male samples of group $B$ and $D$ and in 1(5\%), 3(15\%) and 1(5\%) female samples of group $A, B$ and $C$ respectively.

Conclusion: The shape of the pituitary gland are tended to be changed in between sexes and with advancing ages. It was revealed in the study that, flat glands are more common in male while in female mildly convex gland was common. Rounded glands were found common in male in 50-59 years age group but could not be compared due to absence of female samples from that group. Further studies to find out the cause of this difference of shape between male \& female glands with ages are recommended.

Key Words: Shape, Pituitary gland.

1. Assistant Professor, Department of Anatomy, Dr. Sirajul Islam Medical College, Dhaka.

2. Professor \& Head of the Department of Anatomy, Dhaka Medical College, Dhaka- 1000 .

3. Assistant Professor, Department of Anatomy, Green Life Medical College, Dhaka-1205.

4. Lecturer, Department of Anatomy, Shaheed Suhrawardy Medical College

5. Assistant Professor, Department of Anatomy, Jahurul Islam Medical College.

6. Assistant Professor, Department of Anatomy, Dhaka Central International Medical College

Correspondence : Dr. Mushfika Rahman 
Introduction:

The pituitary gland (hypophysis cerebri) is a reddish grey, ovoid body lies within the hypophyseal fossa of the sphenoid bone, covered superiorly by diaphragma sellae, which is pierced centrally by an aperture for the infundibulum ${ }^{1}$. It is attached to the hypothalamic region of the brain by a narrow stalk and has both neural and vascular connections with the brain ${ }^{2}$. Structurally the gland is divided into a larger anterior region (adenohypophysis) and a smaller posterior region (neurohypophysis). They differ in development, types, arrangement of cells, their vascular and neural supplies. The gland measures about $12 \mathrm{~mm}$ in transverse and $8 \mathrm{~mm}$ in antero-posterior diameter and weighs about 500 $\mathrm{mg}^{1}$. Dynamic changes occur in the size, shape and signal intensity of the pituitary gland during life $^{3}$. These changes reflect the complex hormonal environment of the gland and are most pronounced at times of hormonal flux, such as menarche and pregnancy ${ }^{3}$. Changes in the shape of pituitary gland was evident in some study. The gland tends to be globular in shape at birth and becomes more flattened with age. Previous observers have noted transient changes in the shape or signal intensity of the pituitary gland at different stages of life, which also reflect concurrent changing of hormonal levels ${ }^{3}$. Patient with advanced age had a significantly higher pituitary grade (in shape) ${ }^{4}$. Pituitary adenomas are indolent tumors, which accounts for $10-15 \%$ of all diagnosed intracranial neoplasms ${ }^{5}$.A prospective cross sectional study in the Northern part of Bangladesh reveals that, the prevalence of hyperprolactinemia accounts for about $43 \%$ and $21 \%$ of primary and secondary infertility respectively ${ }^{6}$. Prolactinomas are accounting for about $60 \%$ of primary pituitary tumors ${ }^{7}$. The second most common type is somatotrophic adenoma which is characterized by elevated level of growth hormone- results in gigantism and acromegaly before and after closure of epiphysis respectively ${ }^{8}$. About $25 \%$ of patients have diabetes insipidus ${ }^{9}$.

\section{Materials \& Methods}

Materials:

The present study was performed on 60 post mortem human pituitary glands of different age groups, of which 40 were males and 20 females. Among them, the lowest age was 22 years in both sexes and the highest age was 55 years (male) and 45 years (female).

These entire samples were collected from the whole brains of the unclaimed dead bodies that were under examination in the Department of Forensic Medicine of Dhaka Medical College, Dhaka. The study was approved by the Ethical Review Committee (ERC) of Dhaka Medical College. After accomplishing all legal formalities the samples were collected within $24-36$ hours of death. The samples were brought to the Department of Anatomy, Dhaka Medical College, Dhaka. Soon after collection, each sample was gently washed with tap water on a dissection tray. Blood and blood clots were removed as far as possible. Then the samples were fixed in $10 \%$ formol saline solution.

\section{Methods:}

Place and duration of study: This study was carried out in the Department of Anatomy, Dhaka Medical College, Dhaka, Bangladesh, from July 2009 to June 2010. During collection of the samples appropriate age, sex and the cause of death were noted from the morgue's record book and the samples were tagged bearing code numbers for subsequent identification immediately.

Grouping of the samples: The samples were divided into four groups by decade into age group $A$ (20-29 years), group B (30- 39 years), group C (4049 years) and group D (50-59 years) ${ }^{10}$. Detailed grouping and distribution of samples for morphological study were shown in Table-I.

Table- I

Grouping of the samples

\begin{tabular}{lccc}
\hline Group & $\begin{array}{c}\text { Age limit } \\
\text { in years }\end{array}$ & \multicolumn{2}{c}{$\begin{array}{c}\text { Number of } \\
\text { samples }\end{array}$} \\
\cline { 3 - 4 } & & Male & Female \\
\hline A & $20-29$ & 09 & 09 \\
B & $30-39$ & 17 & 08 \\
C & $40-49$ & 09 & 03 \\
D & $50-59$ & 05 & 00 \\
\hline
\end{tabular}


Observation of the shape of the pituitary glands: After taking the fresh samples on a tray, the shape of the pituitary glands were observed carefully with naked eyes as well as with the help of a hand lens or magnifying glass and noted down. Shape was defined into 5 grades on the basis of concavity/ convexity at attachment of the infundibulum relative to the periphery of the gland.

The grades are as follows ${ }^{11}$

a) Grade 1- Concave.

b) Grade 2- Mildly concave.

c) Grade 3- Flat.

d) Grade 4 - Mildly convex.

e) Grade 5- More convex / rounded / spherical.

Few researchers also found the shape of the pituitary gland as a kidney bean, ovoid body, pea shaped or rounded. These categories were also considered.

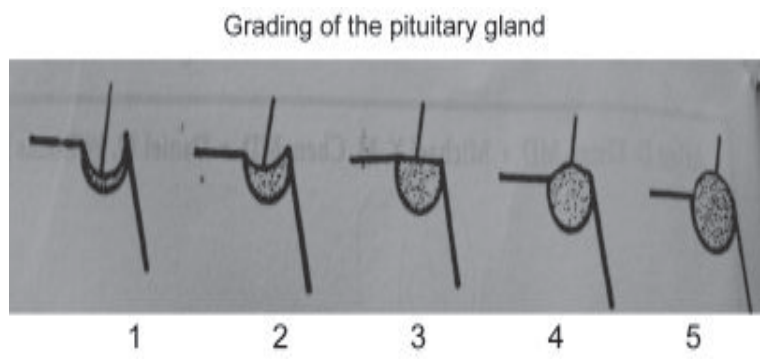

Fig.-1: Shape of the pituitary gland ${ }^{11}$
Results:

Results are shown in the Table -II.

Grade 1 (concave) shape was found in 1(2.5\%) male sample of group $B$ and $C$. The concave shape was absent in other male age groups. The concave shape was present $1(5 \%)$ in female sample of group $A$, but absent in other female age groups. Grade 2 (mildly concave) was noted in 3 (7.5\%), 2 (5\%), 3 $(7.5 \%)$ and $1(2.5 \%)$ male samples of group A, B, C and $D$ respectively. Mildly concave gland was totally absent in all the female age groups.

Grade 3 (flat) was found in 4 (10\%), 5 (12.5\%), 4 $(10 \%)$ and $1(2.5 \%)$ male samples of group A, B, C and $D$ respectively. Flat glands were found in $1(5 \%)$, $2(10 \%)$ and again $1(5 \%)$ female samples of group $A, B$ and $C$ respectively.

Grade 4 (mildly convex) was noted in $2(5 \%)$, $7(17.5 \%), 1(2.5 \%)$ and $1(2.5 \%)$ male samples of group $A, B, C$ and $D$ respectively. Mildly convex gland was found in $6(30 \%), 3(15 \%)$ and $1(5 \%)$ female samples of group A, B and C respectively. Grade 5 (rounded/ spherical) was noted in $2(5 \%)$ male samples of group $B$ and $D$ and was absent in group A and C. Grade 5 was found in 1(5\%), 3(15\%) and $1(5 \%)$ female glands of group A, B and C respectively.

Table - II

Different shape of the pituitary glands of male and female in different age groups

\begin{tabular}{|c|c|c|c|c|c|c|c|c|c|c|}
\hline \multirow{3}{*}{$\begin{array}{l}\text { Shape } \\
\text { Grade }\end{array}$} & \multicolumn{2}{|c|}{ Group A } & \multicolumn{2}{|c|}{ Group B } & \multicolumn{3}{|c|}{ Group C } & \multicolumn{3}{|c|}{ Group D } \\
\hline & \multirow{2}{*}{$\begin{array}{c}\text { Male } \\
\mathrm{n}=9(\%)\end{array}$} & \multirow{2}{*}{$\begin{array}{l}\text { Female } \\
\mathrm{n}=9(\%)\end{array}$} & \multirow{2}{*}{$\begin{array}{c}\text { Male } \\
\mathrm{n}=17 \quad(\%)\end{array}$} & \multirow{2}{*}{$\begin{array}{l}\text { Female } \\
\mathrm{n}=8(\%)\end{array}$} & Male & \multicolumn{2}{|c|}{ Female } & \multirow{2}{*}{$\begin{array}{c}\text { Male } \\
\mathrm{n}=5(\%)\end{array}$} & \multicolumn{2}{|c|}{ Female } \\
\hline & & & & & $\mathrm{n}=9 \quad(\%)$ & $n=3$ & $(\%)$ & & $\mathrm{n}=0$ & $(\%)$ \\
\hline 1 (Concave) & 0 & $1(5 \%)$ & $1(2.5 \%)$ & 0 & $1(2.5 \%)$ & & 0 & 0 & & 0 \\
\hline 2 (Mildly concave) & $3(7.5 \%)$ & 0 & $2(5 \%)$ & 0 & $3(7.5 \%)$ & & 0 & $1(2.5 \%)$ & & 0 \\
\hline 3 (Flat) & $4(10 \%)$ & $1(5 \%)$ & $5(12.5 \%)$ & $2(10 \%)$ & $4(10 \%)$ & 1 & $(5 \%)$ & $1(2.5 \%)$ & & 0 \\
\hline 4 (Mildly convex) & $2(5 \%)$ & $6(30 \%)$ & $7(17.5 \%)$ & $3(15 \%)$ & $1(2.5 \%)$ & & $(5 \%)$ & $1(2.5 \%)$ & & 0 \\
\hline $\begin{array}{c}5 \text { (Convex / rounded } \\
\text { spherical) }\end{array}$ & $\mathrm{d} / \mathrm{d}$ & $1(5 \%)$ & $2(5 \%)$ & $3(15 \%)$ & 0 & & $(5 \%)$ & $2(5 \%)$ & & 0 \\
\hline
\end{tabular}

Group A: Age 20 - 29 years

Group C: Age 40 - 49 years
Group B: Age 30 - 39 years

Group D: Age 50 - 59 years 


\section{Discussion:}

Mildly convex superior margin (grade 4) was found in $6(30 \%)$ female of group A, which was the most common grade of the present study in female group. This finding is very close to that of Wolpert's ${ }^{12}$ and Elster's study ${ }^{11}$. Wolpert's et al. in $1984^{12}$ conducted a study with CT scans of the pituitary glands in 107 women (18-65 years) concluded that convex superior margin was found in 19 patients, more common in younger women (18-36 years) than older (37-70 years). Elster et al. ${ }^{11}$ in 1990 revealed in an MRI study among 169 populations that convex upper margins were noted in 17 out of $32(53 \%)$ girls of 11-22 years. Nearly spherical gland was found in about $8(25 \%)$ of girls in Elster's study ${ }^{11}$, which was similar to the present study, where as $5(25 \%)$ female ranged from $20-49$ years showed grade 5 . In the present study grade 3 (flat) and grade 2 (mildly concave) was found in $14(35 \%)$ and $9(22.5 \%)$ glands in male respectively which almost follow the results of Elster's study ${ }^{11}$, they found that relatively flat or mildly concave shape was more common in male. But grade 4 was the second highest shape in male in this study which was dissimilar to that of Elster's study ${ }^{11}$ where $21 \%$ (18 of 85 ) glands in males were noted with upward convexity. With advancing age, concave superior margin is the common shape revealed by Wolpert et al. ${ }^{12}$, Tien et al. ${ }^{13}$ and Dietrich et al. ${ }^{3}$ found upper border of gland to be flattened with age. But these findings of other researchers were not reflected in this study, may be due to the fewer number of samples from older age groups.

\section{Conclusion:}

The observation and results of the present study are expected to standardize the shape of the pituitary gland in Bangladeshi people. The shape of the pituitary gland are tended to be changed in between sexes and with advancing ages. It was revealed in the study that, flat glands are more common in male while in female mildly convex gland was common. Rounded glands were found common in male in 50-59 years age group but could not be compared due to absence of female samples from that group. Further studies to find out the cause of this difference of shape between male \& female glands with ages are recommended.

\section{References}

1. Crossman AR. ed. Neuroanatomy. In: Standring S, Ellis $\mathrm{H}$, Heally JC, Johnson D, Williams A, Collins P, et al. eds. Gray's Anatomy: The anatomical basis of clinical practice. $39^{\text {th }}$ ed. Edinburgh: Elsevier Churchill Livingstone; 2005. 380-83.

2. Krause wJ. Hypophysis. 2010. Available at- http:/ /web.mac.com/wjkrause/iweb/histology/htm.

3. Dietrich RB, LIs LE, Greensite FS, Pitt D. Normal MR Appearance of the Pituitary Gland in the First 2 Years of Life. AJNR. 1995; 16 : 1413-19.

4. Sharafuddin MJ, Luisiri A, Garibaldi LR, Fulk $\mathrm{DL}$, Klein JB et al. MR Imaging Diagnosis of Central Precocious Puberty: Importance of changes in the Shape and Size of the Pituitary Gland. AJ Roent. 1994;162:1167-73.

5. Hemminki K, Forsti $\mathrm{A}$ and $\mathrm{Ji}$ j. Incidence and Familial risks in pituitary adenoma and associated tumors. Endocrine related cancer. 2007;14: 103-09.

6. Akhter $\mathrm{N}$, Hassan $S$ A.Subclinical hypothyroidism and hyperprolactinemia in infertile women: Bangladesh perspective after universal salt iodination. Int J Endo. 2009;

7. Aron DC, Findling JW, Tyrrell JB. eds. Hypothalamus and pituitary gland. In: Greenspan FS, Gardner DG. eds. Basic and clinical endocrinology. $7^{\text {th }}$ ed. New York: McGraw Hill; 2004.106-63.

8. Maitra A, Abbas KA. eds. Diseases of the endocrine system. In: Kumar V, Abbas AK, Fausto N. eds. Robbins and Cotran pathologic basis of disease. $7^{\text {th }}$ ed. New Delhi: Saunders; 2004. 1156-64.

9. Asa SL. Pituitary Histopathology in Man : Normal and Abnormal. Endotext.com. 2007; Available at-C:|Documents and Settings| userlDesktoplp.t.glptg histopthology.htm 
10. Tsunoda A, Okuda O, Sato K. MR Height of the Pituitary Gland as a function of age and sex: Especially Physiological Hypertrophy in Adolescence and in Climactorium. AJNR.1997;18:551-54.

11. Elster AD, Chen MYM, Williams III DW, Key L L. Pituitary gland: MR Imaging of Physiologic Hypertrophy in Adolescence. Radiology, 1990; 174: 681- 85.
12. Wolpert SM, Molitch ME, Goldman JA, Wood JB. Size, Shape and Appearance of the Normal Female Pituitary Gland. AJR. 1984;143: 377-81.

13. Tien RD, Kucharczyk J, Bessette J, Middleton M. MR Imaging of the pituitary gland in infants and children: Changes in size, shape and MR signal with growth and development. AJR. 1992;158: 1151-54. 